\title{
Modelling infiltration rates in permeable stormwater channels using soft computing techniques
}

\begin{abstract}
In the design of permeable stormwater channels, the ability to quantify infil-tration rates accurately is important for assessing the capability of such chan-nels to perform their required functions. Most of the available infiltrationmodels neglect the effects of water level and channel section on the infiltrationrate. In this study, physical channel models, with different channel sections, were developed in the laborator y and used to measure the infiltration rates.The performance of three soft computing techniques, including Gaussian pro-cess regression, M5P, and random forest (RF) models, were evaluated againstmeasured values. Seven independent input variables, namely, channel sideslope (m), base width (b), water level $(\mathrm{y})$, sand $(\%)$, silt $(\%)$, clay (\%), and time(T) and the output variable infiltration rate $(\mathrm{f}(\mathrm{t}))$, were considered in the modeldevelopment and validation. The Gaussian progression-Pearson VII universalkernel function model approach was found to perform best for the data setconsidered, followed by the RF-based model. The sensitivity investigationshowed that time, water level, and channel side slope were the most influentialinput variables in predicting infiltration rates for permeable stormwater chan-nels and should be given primary consideration in designing such channels.
\end{abstract}

Keyword: Channel section; Infiltration rate; Physical modelling; Soft computing; Water level 